Portland State University

PDXScholar

University Honors Theses

University Honors College

8-1-2017

\title{
Empathy in the Multicultural Classroom
}

Selene Rasmussen

Portland State University

Follow this and additional works at: https://pdxscholar.library.pdx.edu/honorstheses

Let us know how access to this document benefits you.

\section{Recommended Citation}

Rasmussen, Selene, "Empathy in the Multicultural Classroom" (2017). University Honors Theses. Paper 475.

https://doi.org/10.15760/honors.475

This Thesis is brought to you for free and open access. It has been accepted for inclusion in University Honors Theses by an authorized administrator of PDXScholar. Please contact us if we can make this document more accessible: pdxscholar@pdx.edu. 
Selene Rasmussen

Portland State University Honors College

Undergraduate Thesis 2017

Empathy in the Multicultural Classroom 


\section{Empathy in the Multicultural Classroom}

\section{Introduction}

The development and practice of empathetic behavior is a crucial part of the human developmental experience. There is an ongoing effort to attain a deeper understanding of the many correlated factors that contribute to the complex process of empathy construction. The academic knowledge that exists thus far around the importance of the empathetic developmental process is well-documented and argues that empathy is a critical life skill that undergoes rapid development in early childhood (Eisenberg et al, 1996, Hoffman, 2000, O’Neil, 1996, \& Willis, 2015). While some literature exists on the intersection of multicultural experiences and empathy development (Kharkhurin, 2008, \& Pagini et al, 2010), this area is relatively new and has a lot of room for more research to be conducted.

My project proposes and strives to investigate the question of how the development of empathetic behavior is practiced and supported in a public multicultural Head Start preschool classroom.

\section{Literature Review}

The goal of this project is to synthesize and expand upon the growing body of knowledge around empathy development to better understand how it is supported and practiced in a multicultural early childhood education classroom setting. As the fields of study around empathy research have often been multi-disciplined, referencing materials 
from a range of diverse fields yields the most holistic understanding of the complex topic.

While closely related to other pro-social skills like sympathy and compassion, empathy is uniquely defined as having the important distinction of feeling 'with' another as opposed to feeling 'for' another (Gerdes, 2011). In our increasingly diverse modern world, the need to understand and support the development of empathy is greater than ever. Effective citizenship in a multicultural society, and especially within a democratic system of government as seen here in the United States, requires individuals to practice values that promote equality and social justice among culturally diverse groups of others (Banks et al, 2001). These ideas connect directly to the process of empathy development in early childhood as a cornerstone of laying the foundation for effective global citizenship later in life.

Research shows that pro-social behavior such as empathy is a fundamental part of social and emotional development in early childhood and is linked to well-being, flexibility, and resilience later in life (Davidson \& McEwen, 2012). Empathy is an example of pro-social behavior that can begin as early as at the newborn stage, where babies display empathetic distress crying (Hoffman, 2000), and continues to develop throughout the preschool and early education years. From a social standpoint, empathy development is extremely important, as it is part of the process of developing selfregulation skills that are necessary in making the transition from a child being externally regulated (by parents and teachers, for example) to being able to internally regulate themselves in accordance with social and emotional societal norms (Willis, 2015). Learning to operate within these social and emotional norms of a society is a hallmark 
of healthy human development and will ensure future opportunities for success. From a neuroscience standpoint, the development of empathy is a very complex process that requires metacognition, processing of the separation between self and others, and the ability to recognize and label emotions (Hoffman, 2000). Children who are able to display cognitively mature skills like empathy are able to exercise the executive functioning capacities of their brain, located in the frontal cortex. The frontal cortex also houses other related essential life skills sets such as working memory, impulse control, and attention. Recognizing the neural location of empathetic skills allows for a greater understanding to be developed around it's importance in overall human behavioral development. Furthermore, connecting empathetic development with these other essential life skills also allows for connections to be made between empathy and various types of core developmental milestones.

In an educational environment, the practice and development of empathetic skills are especially crucial for not only students, but teachers as well. Teachers have a powerful role in facilitating and demonstrating empathy within their classrooms. Multicultural classrooms present a unique setting for the development of empathy because of the great diversity of language, social class, ethnicity, and culture that exists within them. Here, students begin to develop the knowledge, attitudes, and skills they will need to interact positively with people from diverse backgrounds in their present and future civic life (Banks et al, 2001). The working definition for empathy from the perspective of the teacher in early childhood education is the ability to feel what the child is feeling, understand why the child is feeling, communicate that understanding to them, and then respond in ways that meet their needs (Peck et al, 2015). As one of the 
many important goals of an educator is to prepare their students to be successful out in the greater world, developing empathetic behavior is essential in order to meet student needs. Supporting and modeling the development of empathetic skills in early childhood that will later allow children to effectively communicate and cooperate with diverse populations of others that surround them is no small task. As previously noted, the United States is a place where empathetic skills are especially crucial as our society is uniquely diverse and will only continue to become more so as time goes on. As a function of expanded global connectivity, the future generation of US citizens that are currently in the education system will become global citizens on a level that has never been seen before. Faced with this future, it is imperative that our generation does everything in our power to ensure the success of the next generation in our evolving society. The concept of a great responsibility to prepare our students to become global citizens links directly to the idea of empathy development as a cornerstone for this process. Only with a high degree of competence in the ability to communicate and connect with diverse others will our students of today be successful in the future. Yet meeting these needs is a challenging process that is not aided by the fact that little knowledge exists around empathy development in direct connection to multicultural populations. Therefore, this topic must be explored further.

\section{Method}

Context of Study and Participants

This study took place as part of a larger-scale study on children's language use and acquisition entitled $A$ Year in Stories: Story Circles in the Preschool Classroom as 
conducted by Dr. Erin Elizabeth Flynn. Flynn's study also focused on a multicultural, diverse, early childhood education classroom population, which allowed for these two studies to efficiently pull data from the same classroom populations. The classrooms from which data was taken were two Head Start preschool classrooms, a morning class and an afternoon class, in total encompassing 28 children and three teachers. Each class has one appointed lead teacher and two assistant teachers. These classrooms operate from a play-based, creative curriculum model and are made up of a mixedgender and mixed-age group (3-5 year olds) of children from the local community. The mean for the age of the sample is 54.48 months ( 4.54 years old). In terms of gender, $54.8 \%$ of the class has been identified by the study as male and $45.2 \%$ has been identified as female. There is a multicultural and multi-racial composition of children and their families in the classroom, with multiple languages spoken at home in addition to English. The parent-reported home languages for the sample are $48.4 \%$ speak English as the primary language in the home, $19.4 \%$ Spanish, 12.9\% Arabic, 9.7\% Somali, 3.2\% Creole, 3.2\% Russian, 3.2\% with more than one language spoken as the primary language in the home.

Only minimal data was gathered on classroom teachers; however, the classroom did have a lead teacher, assistant teacher, and classroom aide. The lead teacher held a Bachelor's degree and the classroom maintained at least one bilingual teacher throughout the year. 


\section{Data Collection}

Data collection for this study utilized a participant observation method to document children's interactions and experiences during activities and periods of free play as they happened throughout the day in the classroom. Participant observation was chosen over direct observation due to the realities of occupying space in a preschool classroom where children view adult figures as being in a teacher-like role where they may initiate interaction or ask for assistance at any time. Thus, maintaining pure direct observation with little to no interaction with the observed population during data collection would have been unreasonable, as well as having the potential to do harm in ignoring children's attempts at interaction with the researcher. Observations were recorded by hand in the form of field notes that were later used in the coding process.

\section{Data Analysis}

Data analysis for this project was done in many forms as well. During the active data collection process, an informal memo was created each week, encompassing two sets of observations taken from the previous week. These memos included field note data as well as the researcher's own thoughts and reflections around beginning steps of analysis of the data. Throughout the active data collection process, there were also weekly debriefing meetings held with other members of the research team in which potential emerging patterns in the data were discussed. At the conclusion of the Head Start school year when the active data collection process came to an end, further data analysis was conducted. Field notes were open-coded by hand and a coding key was 
developed and then discussed with members of the research team. Coding procedures were based off the recommendations from authors Merriam (2009) and Miles and Huberman (1994) in their articles on beginning the data coding process. The coding process was altered and further refined through multiple meetings with Dr. Flynn in which the process of developing efficient codes was extensively discussed.

The coding system was developed over a period of time as a result of closely examining observational data and applying applicable codes. Observational data from field notes underwent multiple attempts at coding and underwent changes in codes as the researcher determined the prevalence and usefulness of some codes over others. When a finalized version of the codes were created, a coding key was developed and put into a table (see Table 1 below) for ease of reference. Using these codes, the researcher gathered observational data events and organized them into categories, which then allowed for the data to be examined on a more analytical level. From this organized data, the researcher then identified emerging patterns that could be further analyzed in order to attempt to answer the research question. 


\section{Table 1- Coding Key}

\begin{tabular}{|c|c|}
\hline A.tbreviation: Ccde & Detinition \\
\hline I : I moathy & $\begin{array}{l}\text { Demnnatration of emnathatin he }=\text { avior, } \\
\text { followirg empathet } s \text { clas:room scripts }\end{array}$ \\
\hline E-g: Empatiny via g fl-giving & $\begin{array}{l}\text { Denonstration of emoathelic beravior by } \\
\text { giving a } \mathrm{g} \text { ft to another }\end{array}$ \\
\hline E- pa: Empathy vis physical affection & $\begin{array}{l}\text { Demonstration of emoathelic beravior by } \\
\text { cemonstration of plysical affection }\end{array}$ \\
\hline $1-1:$ mpathy via lang age & $\begin{array}{l}\text { Demnnatration of emnathatin heרavior by } \\
\text { language (e ther verba cr nonverbal bcdy } \\
\text { language) usage }\end{array}$ \\
\hline E- h: Empathy via helpirg & $\begin{array}{l}\text { Demonstration of emsath=tis be avior by } \\
\text { helping annther person }\end{array}$ \\
\hline E- s : Errpathy vil sharing & 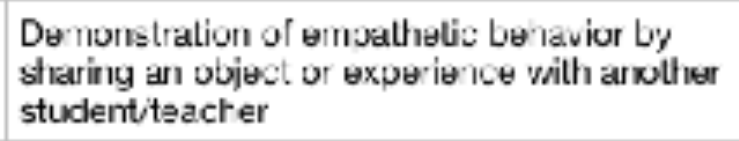 \\
\hline CE : Counter empathy & $\begin{array}{l}\text { Demonstration of non-empathetic behavior, } \\
\text { challengirg empathetic claseroom scripts }\end{array}$ \\
\hline$C \equiv-1$ : Counter-empathy viミ language & 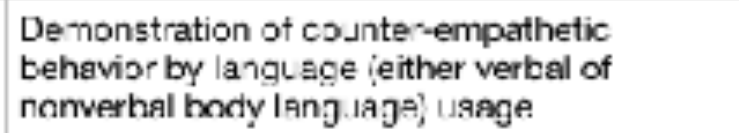 \\
\hline 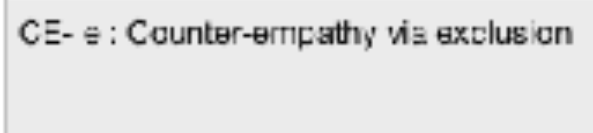 & $\begin{array}{l}\text { Demonstration of counte -umpalhulic } \\
\text { behavior by exclusion of a student, alier ating } \\
\text { them trom other students }\end{array}$ \\
\hline GB: Grous bchavior & $\begin{array}{l}\text { Behavior cccurs in a group setting invelving } \\
2 \text { I sludents }\end{array}$ \\
\hline A.05: 4himation of s-Ffort & $\begin{array}{l}\text { Teacher/student affi mation that sends } \varepsilon \\
\text { signal in support of Anothar teacher/shident } \\
\text { in response to a nehavior }\end{array}$ \\
\hline TPB: Teacl er-prompled belavior & $\begin{array}{l}\text { Teacher-prompled behaviur, allernpls to } \\
\text { encourage students to follow empateetic } \\
\text { classroom scr pts. could incl Jde a teachers } \\
\text { cumriculum materials that pmmpt empathetic } \\
\text { behavior }\end{array}$ \\
\hline S B : Slucent-initialed behavior & $\begin{array}{l}\text { S.udent-initiated beilaviur, allemple lo folkun } \\
\text { (counter)empathetic classroom scripts }\end{array}$ \\
\hline
\end{tabular}


When beginning this project, the focus for documenting observations was on looking to identify events, actions, or language that portrayed the development and/or practice of empathy within this classroom, by both teachers and Head Start students. In the observations of the children in this classroom, actions such as sharing that demonstrate empathetic cognitive processes were noted and coded accordingly, for example using a code of $E$ to recognize empathy, with sub-codes such as $-s$, to represent how empathy was offered. Additionally, language that demonstrated empathetic thinking was coded, such as interactions where children shifted their focus from their own desires to that of the desires of another while using language would indicate an empathetic behavior to be recorded as E-I.

\section{Results}

Observational data gathered and then analyzed through the coding process eventually yielded three main themes that illustrate how empathetic behavior is practiced and supported in the classroom. Firstly, successful empathetic behavior in the classroom was largely enacted via a modeling and echoing effect that occurred between teachers and young students that is heavily language-based. Secondly, when young students do self-initiate empathetic behavior, it is often demonstrated through actions of sharing and/or helping, in contrast to language-based empathetic behavior. Finally, the practice of counter-empathetic behaviors such as exclusion are not necessarily completely anti-social, and can potentially serve a pro-social and empathetic purpose in a complex fashion. 
Language-Based Modeling and Echoing Effect

The most common instances of empathetic behavior being practiced and supported in the classroom occurred when a teacher took the lead role in modeling empathetic behavior. The practice of modeling examples of empathetic interactions was heavily language-dependent, as teachers used language to explain empathetic concepts at the same time as they modeled them via behavior. After witnessing these events, children displayed an echoing effect where they would copy language from the teacher(s) previous example and apply it to new situations. For example, a common occurrence on the playground is a situation where a child falls down and is upset and/or hurt. While other students usually witness this event happening as well, the first responder in this case is a teacher who recognizes the occurrence of the event with a statement such as "Oh no, you fell down" followed by the empathetic question of, "Are you okay?". The teacher then prompts similar empathetic behavior, using verbal language, from the bystander students by telling them, "Ask them if they're okay". The students then comply and ask the fallen student if they are okay. Following this incident and modeled example, students are more prepared and more likely to ask a classmate if they are okay following a fall on the playground. While the original use of this empathetic language and behavior are not necessarily completely student-initiated, the modeling process by the teacher and echoing effect by the student allows for the student to witness a real-life example of what empathetic language sounds like in their classroom, and apply it to similar situations they may encounter later on. This modeling 
and echoing effect gives students the opportunity to practice, and be supported in practicing, empathetic language as it is valued in the classroom.

Student-Initiated Empathetic Behaviors

Yet children can evoke their own unique methods of displaying empathetic behavior as well. Primary methods of students initiating empathetic behaviors with no direct modeling and/or involvement from a teacher were seen through actions such as sharing and helping behaviors. While these interactions were generally less languagedependent, attempts at sharing and helping other students in the classroom clearly signaled empathetic behavior with similar values to those of empathetic language usage. For instance, in a situation where a child is struggling to complete a task such as opening a popsicle, little to no language can be exchanged and yet one student demonstrates self-instigated empathetic initiative by reaching over, opening it for them, and handing it back to them. This is clearly an empathetic behavior, and yet minimal verbal communication occurs, much in contrast to the teacher modeling and student echoing method of empathetic behavior. Interactions such as these demonstrate that although children may not initiate the same type of empathetic behavior as modeled by teachers, they are very capable of practicing empathetic behavior on their own. Actions of sharing and/or helping other students are crucial pro-social behaviors that students enact in ongoing attempt to understand how empathetic values work in their classroom space. 
Counter-Empathy as Pro-Social Behavior

Counter-empathetic behavior was observed and recorded in order to further illuminate and understand the highly complex nature of empathetic behavior. While empathetic behavior clearly serves a pro-social purpose in classroom relationships in that it seeks to promote cooperation between students, there is also paradoxical relationship between counter-empathetic behaviors and empathy. Often, when students are enacting counter-empathetic behaviors within a group, such as exclusion, they are also conversely enacting empathetic behaviors of inclusion for the other group members. Therefore, counter-empathy occurs when children work to exclude certain students from a group dynamic, and yet empathetic behavior is at the same time being offered to those students who are part of the group dynamic via pro-social instances of cooperation and inclusion. This indicates that exclusion and counter-empathy occurs when engagement is happening elsewhere and certain group affiliations are being strengthened over others. Students are then reinforcing connection with some students through the rejection of those that they are not as willing to connect with. For example, in an instance where a group of self-identified "similar" group members of the same gender claim a space, such as a playhouse, as being "for girl's only", they are simultaneously practicing empathetic and counter-empathetic behaviors. While it is counter-empathetic to exclude boys from the playhouse space and appears to be antisocial, it is paradoxically also an inclusive and pro-social experience for the girls within the group. While the idea of counter-empathy serving a dual purpose is not necessarily true of every situation and could vary greatly depending on the context of the event, this 
concept of counter-empathy being used as a pro-social behavior highlights the incredibly complex nature of empathy in the early childhood classroom.

\section{Discussion}

These conclusions are important contributions to our further understanding of how empathy occurs within the multicultural early childhood education classroom. While this project will not focus on defining why these effects occurred, there are possible hypothesis that can further illuminate the cause and effect behind them. For example, one hypothesis is that the marked difference in empathetic behaviors as demonstrated by teachers and students (the modeling and echoing effect via language, versus student-initiated actions) could be due to the fact that language expression is an incredibly complex process and is therefore harder for children to initiate of their own accord. This hypothesis is especially relevant when the reality that empathy is a complicated skill to learn is considered, meaning that it could be increasingly difficult for young children to practice two complex and mentally-challenging skills (language expression and processing, as well as empathy) at the same time. Thus, children are more likely to demonstrate empathy via direct actions and limited verbal language exchange. This hypothesis could connect especially well to a multicultural classroom environment where children may be coming in with varying levels of English language competency and/or experience developmental delays in language usage as a result of learning multiple languages at once. These factors would increase reliance on actionbased empathetic behaviors in order to compensate for a lower level of English language communication skills in regard to empathy. While there is a lack of data to 
correlate directly to these hypotheses, their ability to explain this discrepancy makes it worth considering as an explanation, especially in the case of moving forward with this particular study.

Another hypothesis that is an important take-away from this project's various conclusions is the paramount importance of teachers (as well as other role-model figures such as parents, older siblings, etc) as empathetic behavior models in a young child's life. As illustrated by the observed modeling and echoing effect, empathetic behaviors demonstrated by teachers were the most influential source of all empathetic behavior in the classroom. This acknowledges the incredible amount of power that teachers have to create a classroom where empathetic behavior is supported and encouraged. Furthermore, this hypothesis can be extrapolated onto other types of behavior as well as other role-model figures. For example, counter-empathetic behavior as demonstrated by a teacher, or other role-model figure such as a parent, is likely to be mirrored by young children following the same modeling and echoing effect. The double-edged sword nature of this conclusion emphasizes how crucial it is for teachers and other role models to young children to be cognizant and purposeful in modeling positive empathetic behavior.

Finally, and as previously mentioned, this project demonstrates the importance of recognizing the incredible complexity around empathetic behavior in the early childhood classroom. The dynamic nature of empathetic behavior as shown by this data, coupled with the observed effect where counter-empathetic behavior is not necessarily recognized as completely anti-social, highlights the concept that the multicultural 
classroom is a place full of complex understandings of social worlds for both students and teachers alike.

Overall, this study's results concur with previous literature in many ways that further acknowledge the importance of empathetic skill development in the early childhood years. This project's conclusions also agree that empathetic skills are especially pertinent in a multicultural environment where positive interaction between groups of diverse others is necessary in order for cooperation and progress. Understanding how this process begins in a multicultural early childhood education classroom and what this looks like in practice is the first step in being able to identify strengths that can be used in the future to promote empathetic skill development for future generations, as well as gain a better understanding of empathetic development as a whole.

\section{Limitations and Strengths}

This study is important in its contributions and moves forward our understanding of how empathy development occurs in a multicultural preschool classroom setting. Even with the contributions many limitations exist and must be acknowledged. For instance, this study was done on a small scale. While this allowed for data to be taken more in-depth and granted the opportunity for close analysis, a larger-scale study including observations from more students, classrooms, and teachers would yield much larger amounts of informational data. A larger yield of data could then have been synthesized into a greater diversity of codes. A wider variety of codes could provide firmer footing in establishing overall patterns that emerge from the data upon reaching 
the analysis process. With increasingly more data behind the coding and analysis process, the opportunity for more impactful assertions about the patterns of the data could be secured.

Looking forward into the future, this area of study could also benefit greatly from a comparative study in a more mono-cultural classroom. A compare-and-contrast method of doing this kind of study would be especially effective for isolating how the multicultural component of an early childhood classroom effects empathetic skill development. Additionally, repeated efforts to replicate this study in other multicultural classrooms would greatly add to the depth of knowledge that could be drawn from those conclusions. As each classroom is unique in it's composition, curriculum, and setting, multiple studies surrounding this topic would provide a more general and less sitespecific view of how empathetic skills are developed in early childhood classrooms across the country. Considering potential future studies around this same topic area, a way to gain a deeper understanding of empathy in the classroom would be to include teacher's voices more directly in the data-gathered portion of the study. This could include interviews that question how empathy is explicitly and/or implicitly incorporated into their curriculum, and how they see empathetic skill development being most successfully accomplished. Having teachers as direct sources of knowledge could greatly increase the quality and understandability of the data in this process.

While the acknowledgment of these limitations and suggestion of improvements for future studies within this content area are essential to include, this particular study also has many strengths. For example, the way that data was gathered directly from a multicultural early childhood education classroom allows for the conclusions to be very 
applicable in practice and in real, everyday classroom life. Furthermore, the coding key as developed within this study provides a solid foundation for other researchers to use when approaching empathetic behavior in action in the classroom. This key is flexible and could be expanded and/or revised to fit individual classroom environments, but nevertheless resembles an important first step in approaching this type of research. These positive components of the study among others set the stage for further acceleration and progression of our understanding and knowledge around the concept of empathetic development in early childhood education.

\section{Conclusion}

In conclusion, this project has served a critical role in expanding the body of knowledge that currently exists around understanding empathetic development in an early childhood education setting. Combining the conclusions from this project with the knowledge from previous authors and studies has allowed for a deepened understanding of this topic area. From here, future studies can lean on this solid foundation to more fully explore the topic of early childhood empathetic development. The continuation of study in this area is imperative and will greatly benefit our future citizens, serving as a catalyst for their successful participation in a more globally connected and empathetic world. 
References and Working Bibliography

Banks, J., Cookson, P., Gay, G., Hawley, W., Irvine, J., Nieto, S., Schofield, J., \& Stephan, W. (2001). Diversity within unity: Essential principles for teaching and learning in a multicultural society. Phi Delta Kappan International, 83(3), 196-203.

Bialystok, E., Craik, F.I.M., Grady, C., Chau, W., Ishii, R. \& Gunji, A. (2005). Effect of bilingualism on cognitive control in the Simon task: Evidence from MEG. Neurolmage, 24(1), 40-49.

Birch, B. (2011). The English language teacher in global civil society language, negotiation and peace: The use of English in conflict resolution. Location: Routledge.

Boler, M. (1997). The risks of empathy: Interrogating multiculturalism's gaze. Cultural Studies, 11(2).

Coelho, E. (1998). Teaching and learning in multicultural schools: An integrated approach. Bristol: Multilingual Matters Ltd.

Chang, J., Le, T. (2010). Multiculturalism as a dimension of school climate: The impact on the academic achievement of Asian American and Hispanic youth. Cultural Diversity and Ethnic Minority Psychology, 16(4), 485-492.

Cole, M. (1998) Can cultural psychology help us think about diversity?. Mind, Culture, and Activity, 5(4), 291-304.

Constantine, M., Gainor, K. (2001). Emotional intelligence and empathy: Their relation to multicultural counseling knowledge and awareness. Professional School Counseling.

Davidson, R.J., McEwen, B.S. (2012). Social influences on neuroplasticity: Stress and interventions to promote well-being. Nature Neuroscience, 15, 689-685.

Dewaele, J. (2009). The effect of multilingualism/multiculturalism on personality: No gain without pain for third culture kids?. International Journal of Multilingualism, 6(4).

Dilg, M. (2003). Thriving in the multicultural classroom: Principles and practices for effective teaching. Location: New York: Teachers College Press.

Eck, D. "From Diversity to Pluralism." The Pluralism Project. Harvard University, n.d. Web. 29 Nov. 2016.

Eisenberg, N., Fabes, R.A.,.; Karbon, M., Murphy, B.C., Wosinski, M., Polazzi, L.,Carlo, G., \& Juhnke, C. (1996). The relations of children's dispositional prosocial behavior to emotionality, regulation, and social functioning. Faculty Publications, Department of Psychology. 129. 
Gerdes, K. (2011). Empathy, sympathy, and pity: 21st century definitions and implications for practice and research. Journal of Social Service Research, 37(3), 230-241.

Glauco De Vita (2001) Learning styles, culture and inclusive instruction in the multicultural classroom: A business and management perspective. Innovations in Education and Teaching International, 38(2), 165-174.

Globetti, E., Globetti, G., Brown, C., \& Smith, R. (2015). Social interaction and multiculturalism. NASPA Journal, 30(3).

Hoffman, M. (2000). Empathy and moral development: Implications for caring and justice. Location: New York University. Cambridge University Press. (Book)

Johnston, I. (2000). The difficulty with difference in teacher education: Toward a pedagogy of compassion. Alberta Journal of Educational Research, 75.

Kendall, F. E. (1983). Diversity in the classroom: A multicultural approach to the education of young children. Location: New York: Teachers College Press. (Book).

Kohler-Evans, P., \& Barnes, C. D. (2015). Civility, compassion, and courage in schools today: strategies for implementing in K-12 classrooms. Location: London. Rowman and Littlefield. (Book).

Kharkhurin, A.V. (2008). The effect of linguistic proficiency, age of second language acquisition, and length of exposure to a new cultural environment on bilinguals' divergent thinking. Bilingualism: Language and Cognition, 11(2), 225-243.

Lalas, J. (2007). Teaching for social justice in multicultural urban schools: Conceptualization and classroom implication. Multicultural Education, 14(3), 17-21.

Le, T., Lai, M., \& Wallen, J. (2009). Multiculturalism and subjective happiness as mediated by cultural and relational variables. Cultural Diversity and Ethnic Minority Psychology, 15(3), 303-313.

Lin, J., Brantmeier, E., \& Bruhn, C. (2008). Transforming education for peace. Location: Charlotte: Information Age Publishing Inc. (Book).

Merriam, S.B. (2009) Qualitative research: A guide to design and implementation. San Francisco: Jossey-Bass.

Miles, M. B., \& Huberman, A. M. (1994). Qualitative data analysis: An expanded sourcebook. Thousand Oaks: Sage Publications. 
Murawski, M. From the radio to the museum: Storytelling, listening, and radical empathy. Art Museum Teaching 11 Oct. 2016. Web. 28 Nov. 2016.

O’Neil, J. (1996). On emotional intelligence: A conversation with Daniel Goleman. Educational Leadership.

Pagani, C., \& Robustelli, F. (2010). Young people, multiculturalism, and educational interventions for the development of empathy. International Social Science Journal.

Peck, N.F., Maude, S.P., \& Brotherson, M.J. (2015). Understanding preschool teacher's perspectives on empathy: A qualitative inquiry. Early Childhood Education Journal, 43(3), 169-179.

Ramsey, P. (2004). Teaching and learning in a diverse world: Multicultural education for young children. Location: New York. Teachers College Press. (Book).

Verkuyuten, M. (2007). Social psychology and multiculturalism. Social and Personality Psychology Compass.

Wang, Y., Davidson, M., Yakushko, O., Savoy, H., Tan, J., \& Bleier, J. (2003). The scale of ethnocultural empathy: Development, validation, and reliability. Journal of Counseling Psychology, 50(2), 221-234.

Willis, E. (2015). An empathetic beginning in education: Exploring the prospects of selfregulation skills on pro-social behavior in the early childhood environment. Early Child Development and Care, 186(4). 